\title{
High Flow Nasal Cannula (HFNC) during flexible bronchoscopy, is it cost-effective?
}

\author{
Gaurav Gautam ${ }^{1}$, PRAWIN KUMAR ${ }^{2}$, and Jagdish Goyal ${ }^{2}$ \\ ${ }^{1}$ All India Institute of Medical Sciences - Jodhpur \\ ${ }^{2}$ All India Institute of Medical Sciences Jodphur
}

September 30, 2021

Type of Study : Letter to Editor

Full Title : High Flow Nasal Cannula (HFNC) during flexible bronchoscopy, is it cost-effective?

Gaurav Gautam MD, Prawin Kumar MD, Jagdish P. Goyal MD

Department of Pediatrics, All India Institute of Medical Sciences Jodhpur, Rajasthan, India

Abbreviated title: HFNC during flexible bronchoscopy

Authors details:

Dr. Gaurav Gautam, MD, Senior Resident, Department of Pediatrics, All India Institute of Medical Sciences Jodhpur, Rajasthan, 342005. Email: gauravgautam1912@gmail.com

Dr. Prawin Kumar, MD, Associate Professor, Department of Pediatrics, All India Institute of Medical Sciences Jodhpur, Rajasthan, 342005. Email: drprawin484@gmail.com

Dr. Jagdish Prasad Goyal, MD, Additional Professor, Department of Pediatrics, All India Institute of Medical Sciences Jodhpur, Rajasthan, 342005. Email: goyal.drjagdish@gmail.com

\section{Corresponding Author}

Dr. Prawin Kumar

Associate Professor, Pediatrics,

All India Institute of Medical Sciences Jodhpur,

Rajasthan, 342005. India

Email: drprawin484@gmail.com

Phone: 9540084230

Word count: Manuscript- 560, Reference: $\mathbf{5}$

Conflict of interest: None

Funding: None

Disclosures: None

Acknowledgment: None

Author's contribution. 
GG : conceptualization, manuscript writing and literature review. PK : conceptualize, prepare an initial draft, and literature review JPG: conceptualization, manuscript writing, and literature review. All the author critically reviewed the final version of the manuscript and approved for the publication. PK will act as guarantor for this manuscript.

\section{Hosted file}

Letter to Editor.docx available at https://authorea.com/users/438754/articles/539851-highflow-nasal-cannula-hfnc-during-flexible-bronchoscopy-is-it-cost-effective 